\title{
Progressive myoclonus epilepsy without Lafora bodies
}

\author{
W. B. MATTHEWS, ${ }^{1}$ D. A. HOWELL, AND D. L. STEVENS ${ }^{2}$ \\ From the Derbyshire Royal Infirmary
}

Many attempts have been made to define consistent clinical and pathological entities within the syndrome of progressive myoclonus epilepsy. The existence of a specific metabolic defect underlying one form of the disease is suggested by the presence of characteristic cerebral inclusion bodies (Lafora and Glueck, 1911) and of material with similar staining properties in liver and muscle (Harriman and Millar, 1955). Several authors (van Heycop ten Ham and de Jager, 1963; Schwarz and Yanoff, 1965) have maintained that this Lafora-positive group presents an almost uniform clinical development. Preceding generations are free of epilepsy but parental consanguinity is common and more than one child often has the disease. The age of onset is between 10 and 17, sometimes preceded by some years by an isolated fit. The duration of the disease is from two to 10 years. The myoclonus becomes almost continuous and is not accompanied by loss of consciousness, although major fits are often preceded by a violent increase in myoclonus. Dementia and ataxia are common, the latter often difficult to distinguish from the effects of incessant myoclonus. Visual failure is rare. Diffuse muscular atrophy is marked in the terminal stages. The electroencephalogram (EEG) shows diffuse slow activity and spike and wave transients.

Deviations from this clinical picture such as an earlier or later age of onset, visual failure as the first symptom, lack of progression, absence of dementia, or the presence of the syndrome in preceding generations have been thought to be associated with other pathological findings, either lipidosis or non-specific degenerative changes. With the exception of parental consanguinity the family reported here fulfils all the clinical criteria that have been regarded as typical of the Lafora-positive form of progressive myoclonus epilepsy but no Lafora bodies were present.

\section{CASE REPORT}

Jennifer H (DRI 304011) was admitted to the Derbyshire Royal Infirmary in February 1966 at the age of 15. She

${ }^{1}$ Present address: Department of Neurology, the Manchester Royal Infirmary.

'Present address: the General Infirmary, Leeds. had been born after a normal delivery and had no serious illness in early childhood apart from scarlet fever $\stackrel{0}{\rightarrow}$ followed by whooping cough at the age of 5 .

When she was 11 she developed jerking movements of the hands that would cause her to drop objects she was $\overline{\bar{c}}$. holding. Soon afterwards she began to have infrequent $\overparen{\nabla}$ generalized convulsions with loss of consciousness. Both $\varrho$ the involuntary movements and the fits increased in क frequency and severity and she became severely in- $\overrightarrow{0}$ capacitated. For over a year she had been unable to walk unaided and could feed herself only with difficulty. The $\vec{\omega}$ fits were now occurring at least twice a week and were $\stackrel{\mathscr{S}}{.}$ usually preceded by a violent increase in the involuntary movements. She had recently been treated with corti- 0 cotrophin in another hospital without benefit.

She was alert and not apparently demented. The optio discs and retinae were normal and visual acuity was no reduced. The pupils and ocular movements were norm得 $\vec{\sigma}$ and hearing intact. Her speech was disturbed b myoclonus involving the face and tongue, but even wher 2 there was no detectable myoclonus she was dysarthric.

The muscles of the limbs and trunk were involved is almost continuous myoclonus. This occurred asynchroe ously and asymmetrically without any consistent patterm. $\overrightarrow{8}$ Even during relatively quiet periods she was unable to 8 walk or stand, apparently due to ataxia. Strength was difficult to estimate but was probably normal. The ankle jerks were absent but the other tendon jerks were normal and the plantar reflexes were flexor. There was no sensory loss.

She had a moderate degree of dorsal scoliosis but no pes cavus.

She had severe acne due to corticotrophin and her face was rounded. The limbs and trunk were unduly thin but there was no localized muscle atrophy.

During her stay in hospital she was observed to have major epileptic fits, each preceded by a progressive increase in the already severe myoclonus over several hours.

INVESTIGATION Routine examination of the blood and urine, blood urea, liver function tests, and Wassermann reaction showed no abnormality. She had small bilateral cervical ribs. Radiographs of the skull were normal.

No metachromatic material was present in the urine. A rectal biopsy showed no evidence of lipidosis. Fractionation of the serum mucopolysaccharides (Dr. D. W. Neill) showed no disturbance of the alpha-2 N component.

Electroencephalograms (Fig. 1) showed a rapid $\tilde{O}$ posterior rhythm around $20 \mathrm{~Hz}$. When the eyes were ${ }_{\omega}$ closed multiple diffuse spike discharges occurred about 


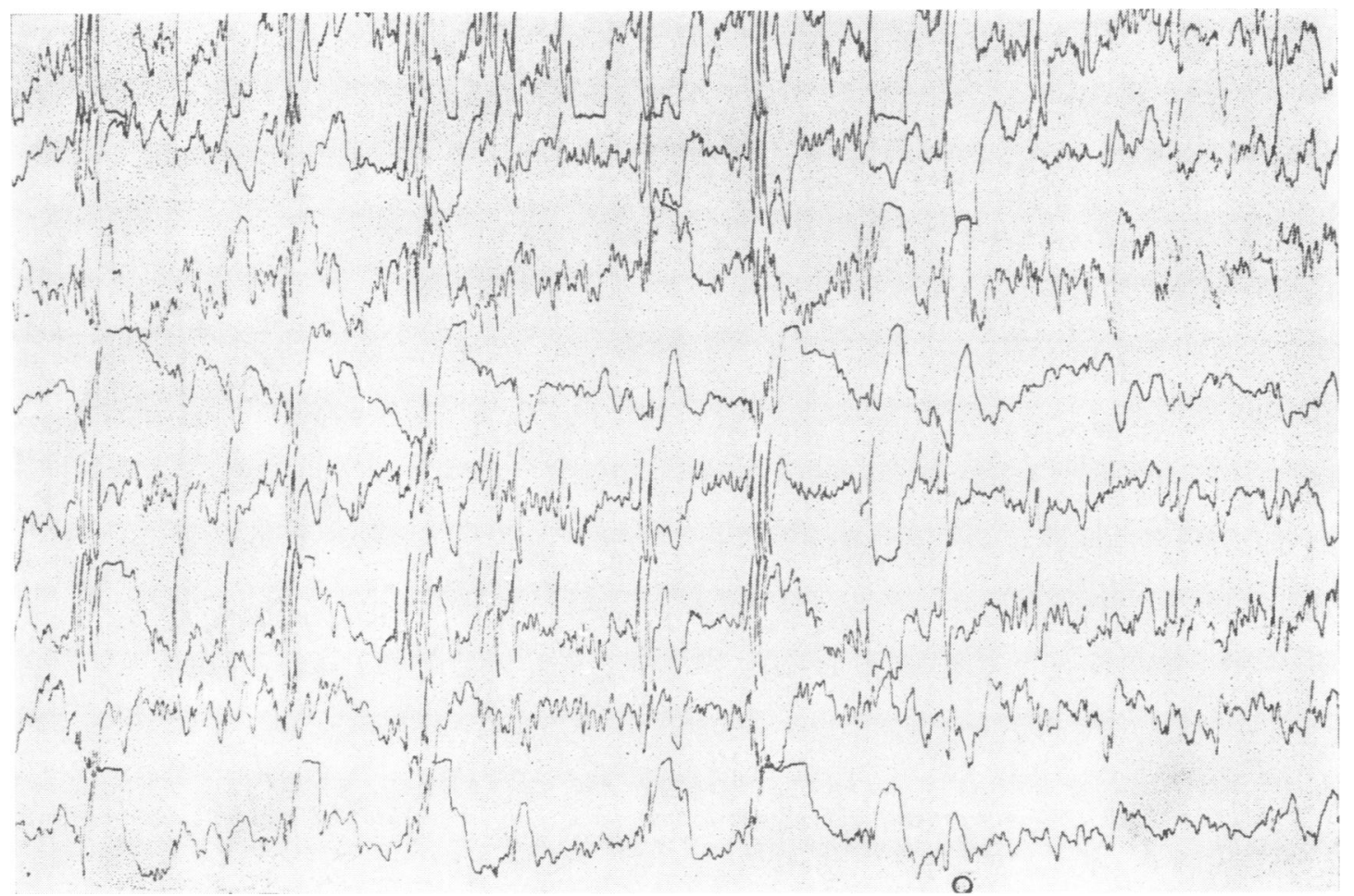

FIG. 1. EEG in February 1966 showing almost continuous spike discharges, partially inhibited by opening the eyes $(O)$. (Montage and calibrations as in Figure 2.)

once a second, although not regularly. Many of these discharges appeared to be synchronous with myoclonus but precise observation was impossible. Opening the eyes caused a marked reduction in the spikes but not of the myoclonus. Flicker stimulation with the eyes open induced bifrontal spikes.

Her IQ was 93 and selective tests showed no evidence of mental deterioration at this time.

TREATMENT Conventional anticonvulsants had been extensively tried and had proved ineffective. She was maintained on phenobarbitone $60 \mathrm{mg}$ twice a day and phenytoin $100 \mathrm{mg}$ three times a day, to which was added phenylethylacetylurea (Benuride) $200 \mathrm{mg}$ three times a day. At the same time she was given treatment for her infected acne, including tetracycline $250 \mathrm{mg}$ three times a day. She rapidly developed a severe reaction with a fever of $40.5^{\circ} \mathrm{C}$, eosinophilia of $12 \%$, conjunctivitis, and urticaria. Both drugs were stopped and the reaction subsided. Subsequent reintroduction of phenylethylacetylurea without any reaction suggests that it was not responsible. There was an undoubted effect in reducing the myoclonus, paralleled by a reduction in the spike discharges in the EEF (Fig. 2). In particular, spikes were no longer induced by closing the eyes. There was, however, no improvement in her walking or other voluntary movements. The interval between the two recordings illustrated was two months and the change is unlikely to be due to the natural progress of the disease.

She was discharged to her home on the same treatment and seen at intervals. Although she had only occasional major fits and the myoclonus remained less pronounced, her condition deteriorated. Dementia became obvious and her speech was confined to occasional monosyllables. She became progressively emaciated with severe generalized muscular atrophy. She died at home of pneumonia in March 1968 at the age of 17.

PATHOLOGY Necropsy was performed the day after her death by Dr. R. E. Cotton who confirmed that she had severe bronchopneumonia. The brain was small, weighing $1,020 \mathrm{~g}$, but showed no abnormality on external examination. It was fixed in $4 \%$ formaldehyde in saline and sent to Derby. ${ }^{1}$

Coronal sections showed no abnormality except that the cerebellar folia appeared unduly thin.

Many blocks were taken and embedded in paraffin. Sections were stained with haematoxylin and eosin, haematoxylin and van Gieson's stain, by the toluidine blue method, the Loyez method, Holze's method, and by the periodic acid Schiff methed.

Histological abnormalities were confined to the ${ }^{1}$ We are indebted to Dr. Cotton for the opportunity to examine the specimen. 



FIG. 2. EEG in April 1966 on treatment with phenylethylacetylurea, showing marked reduction of spikes, even wit eyes closed $(C)$.

cerebellum. Purkinje cells were almost completely absent, only a few misshapen cells remaining. In their place astrocytes had proliferated to form a layer several cells thick in some areas but not in others, suggesting that the Purkinje cells had been lost at varying times before death (Figs. 3 and 4). The granular cell layer was of normal thickness but with some decrease in cellularity without glial reaction. The white matter of the folia was pale in myelin stained sections and there was an increase in the number of astrocytes, many having paired nuclei. In the white matter around the dentate nuclei there were a few collections of small round cells with little cytoplasm surrounding the small blood vessels. The dentate nucleus and the roof nuclei of the cerebellum showed a trivial loss of neurones compared with control sections. A few binucleated neurones were seen. Glial cells were increased and paired astrocytic nuclei were common. There was no pallor or shrinkage of the superior cerebellar peduncles.

No lesions were recognized in the cerebellar connections in the brain-stem-the red nucleus, the pontine nuclei, the inferior olives, and the vestibular nuclei all appearing entirely normal.

No histological abnormalities were found, on comparison with control sections, in any area of the cerebral cortex or white matter, in the basal ganglia and thalamus, or in the brain-stem.

No Lafora bodies or other inclusion bodies were seen. Corpora amylaceae were almost absent. No cells distended with lipid were present.

Sections of heart muscle showed no material with the staining properties of Lafora bodies.
The spinal cord was not available for examination.

PEDIGREE Her parents were not related and were im. $\vec{\odot}$ good health. Their EEGs were normal, including the response to flicker. No epilepsy was known in preceding generations.

There were eight children (1967), of whom Jennifer was the second. Her brothers, aged 20, 16, 5, and 8 months, and a sister, aged 9 , had no clinical evidence of myoclonus or epilepsy and had normal EEGs including the response to flicker.

A sister, E.H., aged 12, had no symptoms but her EEG showed diffuse irregular spike and slow wave discharges on flicker stimulation. The resting record was normal.

A sister, J.H., developed major epilepsy at the age of 10. The fits increased in frequency to approximately one a week, many being nocturnal. The frequency was not altered by phenobarbitone $30 \mathrm{mg}$ and phenytoin $50 \mathrm{mg}$ twice a day. Soon after the onset of the fits she developed attacks in which her head would shake. This was not witnessed but was described by her mother as being a rapid single jerk of the head occurring infrequently. No myoclonus or other abnormality was seen when she was examined and there was no dementia. The frequency of the fits was much reduced when primidone was substituted for phenobarbitone.

The EEG showed much high voltage slow activity, mainly in posterior leads, and frequent random sharp waves, increased on closing the eyes. Irregular spike and slow wave activity occurred on flicker stimulation. 


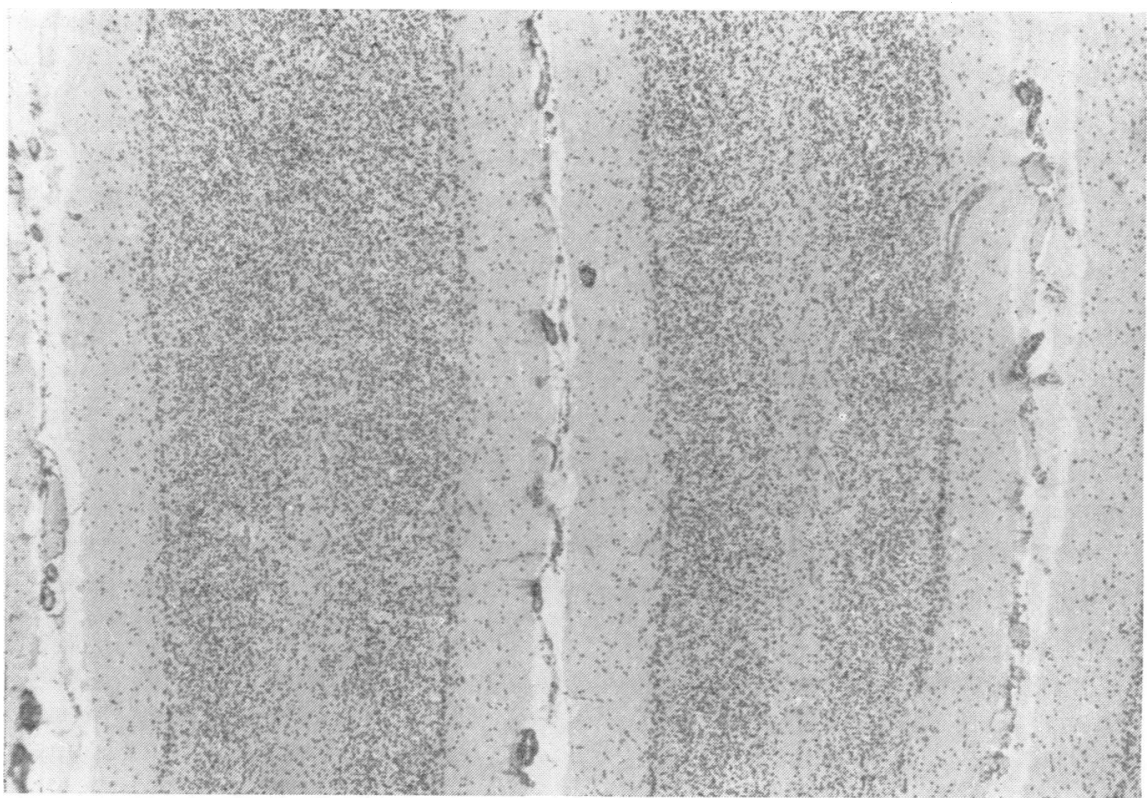

FIG. 3. Cerebellar cortex. Haematoxylin and van Gieson's stain. $\times 120$. Complete absence of Purkinje cells and proliferation of astrocytes.

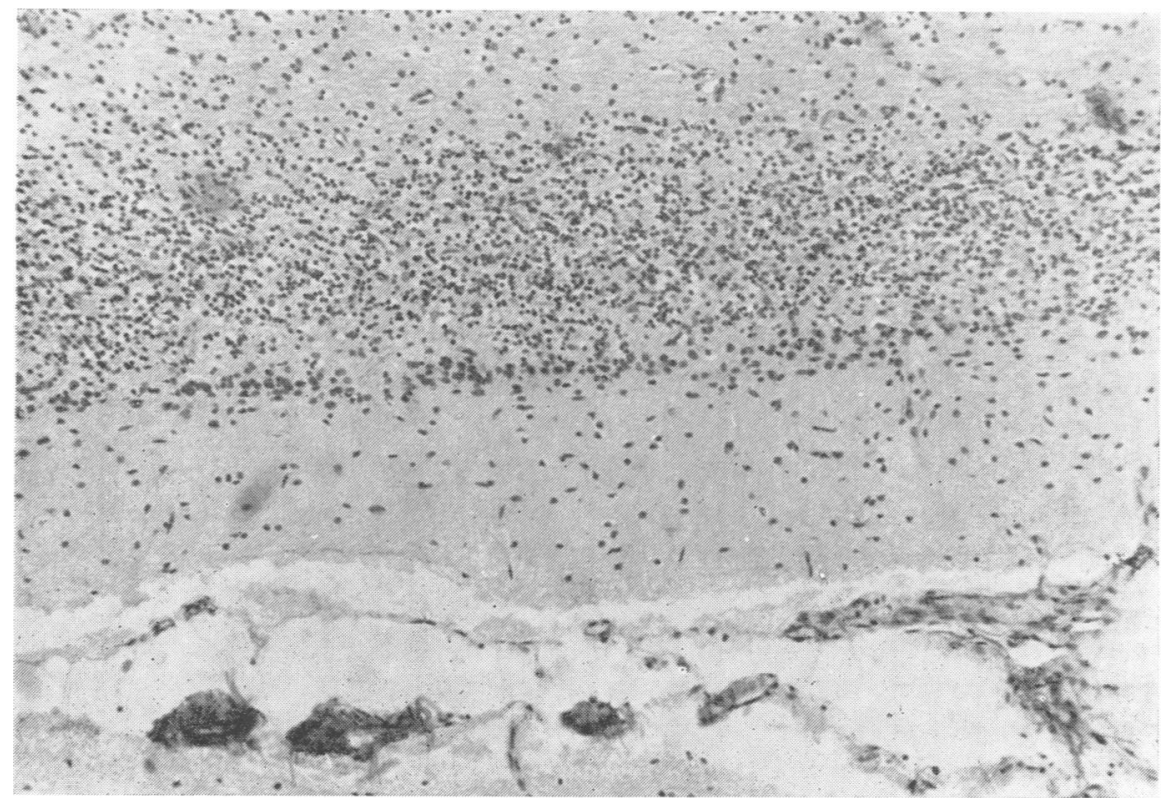

FIG. 4. Cerebellar cortex $\times 330$. Some loss of cells in the granular layer is shown.

DISCUSSION

Progressive myoclonus epilepsy may be defined as recurrent major fits, frequent bilateral myoclonus, and progressive neurological disability, this last feature excluding the myoclonus of idiopathic epilepsy. Myoclonus is common and major epilepsy occasional in subacute inclusion-body encephalitis and in spongiform encephalopathy. Lipidosis, especially late infantile forms (Edgar and Post, 1963; Klincken-Rasmussen and Dyggve, 1965), may rarely present in this way. When the pathology is known the great majority of patients with this syndrome either have Lafora inclusion bodies in the 
central nervous system or 'degenerative' disease of unknown cause.

In recent reviews of the Lafora type the specificity of the clinical features has been over-emphasized (van Heycop ten Ham and de Jager, 1963; Schwarz and Yanoff, 1965). Assuming, as seems highly probable, that the child J.H. is in the early stages of the disease, the family reported here shows that all the clinical criteria can be met without Lafora bodies being present, at least at the time of death. The converse may also be true, as van Hoof and Hageman-Bal (1967) and Diebold, Häfner and Vogel (1967) report Lafora bodies in patients well beyond the accepted age limits for this disease.

The Lafora-negative, degenerative group is less well documented. It is usual to state that in such cases the age of onset is unusually early or late and that the course is often prolonged (Gastaut, 1968). These generalizations are not fully supported by the evidence from the present case and from the 18 fully described and necropsied cases in the available literature. If these are subdivided according to simple clinical criteria certain correlations become apparent.

1. INFANTILE AND LATE INFANTILE This group includes those patients who were retarded from birth and those developing symptoms other than an isolated convulsion before the age of 5 , and consists of six patients in four families. Additional clinical features were choreo-athetosis in the two siblings described by van Bogaert (1929) and localized myoclonus occurring for the first time a few weeks before death in one of the two siblings reported by Morse (1949). There was no evidence of heredity in the case of Fattovich (1955) nor in that of Myle and van Bogaert (1949), although the latter was thought on pathological grounds to have a form of hereditary ataxia. The group is certainly heterogeneous but the pathology does show an unexpected unifying feature. With the exception of Morse's second case the cerebral cortex showed degenerative changes to a degree notably absent in the other groups.

2. ONSET AND DURATION SIMILAR TO THE LAFORA GROUP The patient described in this paper falls into this group and there are four reported cases in whom the age of onset was between 9 and 18 and the duration of the disease was not more than approximately 10 years (Dimitri, 1932; Ammermann, 1940; Yokoi, Kobori, and Yoshihara, 1965). Evidence of heredity is again strong, as in three cases siblings were affected and in the fourth the parents were consanguineous. In contrast with the first group, however, the pathological reports all emphasize the absence of any lesion of the cerebral cortex despite the terminal dementia and we confirmed this finding in our patient.

The clinical features of these patients are indistinguishable from those of the Lafora group. Yokoi et al. (1965) found inclusion bodies quite distinct from the Lafora type in oligodendroglia in $D$ one patient and in neurones of the brain-stem ganglia in another. The patients were unrelated and the inclusion bodies in the two cases did not have identical staining properties.

3. ONSET IN CHILDHOOD WITH PROTRACTED COURSE Of the seven cases in this group the age of onset in five was between 8 and 13 and was not precisely known in two. The age at death varied from 34 to 58. In strong contrast with the other groups there was no evidence of familial incidence in those cases reported by van Bogaert (1949), Henneaux (1958), Franck and Reznik (1967), Curcio and Pedace (1955), Dimitri and Aranovich (1947), and Catalano (1926). The only familial example is Hunt's original necropsied case of dyssynergia cerebellaris myoclonica (Hunt, 1921). This man and his twin brother clearly had Friedreich's ataxia from childhood and developed epilepsy and myoclonus, presumably a $\overrightarrow{\hat{\theta}} \stackrel{-}{-}$ an integral feature of their disease, in the thir $\vec{\sigma}$ decade. Although there is no full agreement th $\bar{\phi}$ 음 coexistence of the clinical or pathological features of spino-cerebellar ataxia and myoclonus is generall $D$ regarded as essential for this diagnosis (Louis-Bas and van Bogaert, 1947; Cristophe and Grunet 1956) but major epilepsy is uncommon.

4. LATE ONSET The patient described by Pallis, Duckett, and Pearse (1967) is the only example where the onset was clearly later than in the Lafora group. This man, who was found to have diffuse lipofuscinosis of the central nervous system, developed the syndrome at the age of 49 and died three years later. There was no family history of similar disease. This case can only doubtfully be classified as 'degenerative'.

This classification is based entirely on cases proved at necropsy not to have Lafora bodies and therefore differs radically from that of Diebold et al. (1967), which was concerned solely with clinical and genetic features, irrespective of the pathology, when this was known.

Watson and Denny-Brown (1953) emphasized that diffuse neuronal disease was important in the production of myoclonus, but in the pathological material reviewed here the lesions were often remarkably localized. Many authors comment on the contrast between the severity of the clinical syndrome, leading to helpless dementia, and the paucity of pathological findings. There are reports 
of comparatively slight loss of neurones in many areas of the brain, varying from patient to patient but often involving the basal ganglia. Much more severe diffuse damage occurs in cases with an early onset of symptoms. In the other main groups the maximum impact was always on the cerebellar cortex, notably the Purkinje cells, the dentate nuclei, or the inferior olives, the emphasis again varying greatly from case to case. Ammermann (1940) found the olives to be the only structures involved; in the present case loss of Purkinje cells was almost the only lesion, while in Hunt's (1921) case the dentate nuclei were severely affected and the cerebellar cortex spared. Hodskins and Yakovlev (1930) drew attention to a rather imprecise clinical association between myoclonus and cerebellar signs in patients with epilepsy. The explanation for the type of spontaneous myoclonus at rest seen in this syndrome certainly appears to lie in some derangement within the olivo-cerebellar complex. Bradshaw's (1954) patient in whom no relevant lesion could be found at necropsy did not have epilepsy and had a different type of action myoclonus but is a forcible reminder of the difficulty of elucidating disturbance of function with the microscope.

The evidence for recessive inheritance is strong in the Lafora type of progressive myoclonus epilepsy and a genetic basis is highly probable in many of those in the degenerative group. EEG abnormalities have been found in clinically unaffected members in such families (Namba, Ota, and Fukunaga, 1966), as in E.H. in the present study, but it is clearly unjustifiable to claim that this is evidence of the carrier state (Sarlin, Kloepfer, Mickle, and Heath, 1960). Assuming recessive inheritance, the only certain heterozygotes are the parents of two or more affected children and here it is known that the EEG may be normal (Delay, Fischgold, Pichot, and Verdeaux, 1947) and in the family reported here.

The investigation of the biochemical abnormalities underlying the various forms of progressive myoclonus epilepsy is more likely to throw light on the pattern of inheritance, but the information at present available is confused. Millar and Neill (1959) first reported a reduction of serum mucoproteins in all members of a family, three of whom had progressive myoclonus epilepsy. It is not known if Lafora bodies are present in this family but the resemblance between the staining properties of the Lafora material and of the mucoproteins was noted. Castaigne, Cambier, Brunet, Schuller, and Chemaly (1967) confirmed this observation but a connection has not been firmly established between any biochemical abnormality in the blood and any specific type of myoclonus epilepsy. There is considerable disagreement on the chemical composition of the
Lafora bodies (Yokoi, Austin, and Witmer, 1966; Janeway, Ravens, Pearce, Odor, and Suzuki, 1967), but a disturbance of carbohydrate metabolism appears probable (Seitelberger, Jacob, Pfeiffer, and Colmant, 1964). The serum alpha-2 polysaccharides have been reported as greatly raised (Bergouignan, Arne, and Loiseau, 1958) and reduced (Tukel and Çaliskan, 1964), and the $\alpha-2$ globulins have also been found to be raised (Lowenthal, 1965). Unfortunately, no anatomical evidence was available in any of these families, but only that of Tukel and Çaliskan (1964) at all resembled the Lafora type. In the present case the serum mucoproteins were not disturbed and there were no Lafora bodies.

\section{SUMMARY}

A family is described in which one child suffered from progressive myoclonus epilepsy and a second appeared to be in an earlier stage of the disease. A suggestive EEG abnormality was found in a third child who was free from symptoms. With the exception of parental consanguinity this family fulfilled all the clinical criteria thought to be characteristic of the Lafora type of progressive myoclonus epilepsy but no Lafora bodies were found at autopsy. The clinical and pathological features of progressive myoclonus epilepsy due to degenerative disease are reviewed.

\section{REFERENCES}

Ammermann, O. (1940). Isolierte Schädigung der unteren Oliven bei Myoklonusepilepsie. Arch. Psychiat. Nervenkr., 111, 213-232.

Bergouignan, M., Arne, L., and Loiseau, P. (1958). Sur la dyssynergie cérébelleuse myoclonique. Rev. neurol., 98, 695-699.

Bradshaw, J. P. P. (1954). A study of myoclonus. Brain, 77, 138-157.

Castaigne, P., Cambier, J., Brunet, P., Schuller, E., and Chemaly, R. (1967). Epilepsie myoclonique progressive familiale, d'hérédité dominante; étude clinique et biologique d'une famille. Encéphale, 56, 285-307.

Catalano, A. (1926). Per la mioclono-epilessia. Studio clinico ed istopatologico. Riv. sper. Freniat., 50, 39-49.

Christophe, J., and Gruner, J. (1956). La dyssynergie cérébelleuse myoclonique de Ramsay Hunt. Etude anatomique d'un cas. Rev. neurol., 95, 297-309.

Curcio, F. I., and Pedace, E. A. (1955). Disinergia cerebelosa mioclónica. A propósito de una observación anatomoclinica. Acta neuropsiquiát. argent., 1, 327-341.

Delay, J., Fischgold, H., Pichot, P., and Verdaux, G. (1947). L'épilepsie myoclonique de type Unverricht. Etude génétique. Constatations électro-encéphalographiques. Rev. neurol., 79, 430-433.

Diebold, K., Häfner, H., and Vogel, F. (1967). Zur Klinik der progressiven Myoklonusepilepsien. Dtsch. Z. Nervenheilk., 190, 199-240.

Dimitri, V. (1932). Observaciones de epilepsia mioclónica familiar con estudio histopatológico. Pren. méd. argent., 18, 1229-1239.

Estudio clinico e histopatológico. Rev. neurol. B. Aires, 12, 246-266.

Edgar, G. W. F., and Post, P. J. J. (1963). Amaurotic idiocy and epilepsy. Epilepsia (Amst.), 4, 241-260.

Fattovich, G. (1955). Sulle mioclonie epilettiche. Rass. Studi psichiat., 44, 587-605.

Franck, G., and Reznik, M. (1967). L'épilepsie-myoclonie progressive d'Unverricht-Lundborg. Etude anatomoclinique d'une forme abiotrophique. Acta neurol. belg., 67, 713-730. 
Gastaut, H. (1968). Séméiologie électro-clinique et nosographie analytique des myoclonies. Rev. neurol., 119, 1-30.

Harriman, D. G. E., and Millar, J. H. D. (1955). Progressive familial myoclonic epilepsy in three families; its clinical features and pathological basis. (With an appendix on the genetic aspects by A. C. Stevenson.) Brain, 78, 325-349.

Henneaux, J. (1958). Une atrophie cérébelleuse sénile fruste sous l'aspect clinique d'une épilepsie-myoclonie progressive avec démence. Acta neurol. belg., 58, 270-275.

Hodskins, M. B., and Yakovlev, P. I. (1930). Anatomo-clinical observations on myoclonus in epileptics and on related symptom complexes. Amer. J. Psychiat., 9, 827-848.

Hunt, J. R. (1921). Dyssynergia cerebellaris myoclonica-primary atrophy of the dentate system; a contribution to the pathology and symptomatology of the cerebellum. Brain, 44, 490-538.

Janeway, R., Ravens, J. R., Pearce, L. A., Odor, D. L., and Suzuki, K. (1967). Progressive myoclonus epilepsy with Lafora inclusion bodies. I. Clinical, genetic, histopathologic, and biochemical aspects. Arch. Neurol. (Chic.), 16, 565-582.

Klincken-Rasmussen, L., and Dyggve, H. V. (1965). A case of late infantile amaurotic idiocy of the myoclonus type. Acta neurol. scand., 41, 172-186.

Lafora, G. R., and Glueck, B. (1911). Beitrag zur Histopathologie der myoklonischen Epilepsie. Z. ges. Neurol. Psychiat., 6, 1-14.

Louis-Bar, D., and van Bogaert, L. (1947). Sur la dyssynergie cérébelleuse myoclonique (Hunt). Mschr. Psychiat. Neurol., 113, 215-247.

Lowenthal, A. (1965). Clinical biochemistry of epilepsy. Epilepsia (Amst.), 6, 198-204.

Millar, J. H. D., and Neill, D. W. (1959). Serum mucoproteins in progressive familial myoclonic epilepsy (a preliminary note) Epilepsia (Amst.), 1, 115-116.

Morse, W. I. (1949). Hereditary myoclonus epilepsy. Two cases with pathological findings. Bull. Johns Hopk. Hosp., 84, 116-127.

Myle, G., and van Bogaert, L. (1949). Sur une hérédoataxie avec démence, épilepsie-myoclonie et arachnodactylie. (Sa situation vis-à-vis de la dyssynergie cérébelleuse myoclonique de Hunt.) Mschr. Psychiat. Neurol., 118, 364-378.

Namba, M., Ota, T., and Fukunaga, S. (1966). The investigation of electroencephalogram of patients suffering from (sic) myoclonusepilepsy (Lafora type) and its family. Brain Nerve (Tokyo), 18, 1165-1173.
Pallis, C. A., Duckett, S., and Pearse, A. G. E. (1967). Diffuse lipo- 으 fuscinosis of the central nervous system. Neurology (Mineapp.), $Z$ 17, 381-394.

Sarlin, M. B., Kloepfer, H. W., Mickle, W. A., and Heath, R. G. (1960). The detection of carriers in hereditary myoclonic epilepsy. Acta Genet. med. (Roma), 9, 466-471.

Schwarz, G. A., and Yanoff, M. (1965). Lafora's disease. Distinct $\underset{\widehat{Q}}{\widehat{Q}}$ clinico-pathologic form of Unverricht's syndrome. Arch. Neurol. (Chic.), 12, 172-188.

Seitelberger, F., Jacob, H., Pfeiffer, J., and Colmant, H. J. (1964). Die Myoklonuskörperkrankheit. Eine angeborene Störung des Kohlenhydratstoffwechsels. Klinisch-pathologische Studie an funf Fällen. Fortschr. Neurol. Psychiat., 32, 305-345.

Tukel, K., and Çaliskan, A. (1964). L'étude électroencéphalographique :d'une famille dont deux membres sont atteints d'épilepsie myoclonique d'Unverricht-Lundborg. Rev. neurol., 110, 只 231-246.

van Bogaert, L. (1929). Sur une variété non décrite d'affection familiale: l'épilepsie myoclonique avec choréo-athétose. Rev. neurol., 36, 385-414.

- (1949). Sur l'épilepsie myoclonique progressive d'Unverricht- $\mathbb{D}$ Lundborg. Etude d'un cas anatomique et de les semiologie du syndrome amyostatique terminal. Mschr. Psychiat. Neurol., ஹ) 118, 170-191.

van Heycop ten Ham, M. W., and de Jager, H. (1963). Progressive $\vec{O}$ myoclonus epilepsy with Lafora bodies. Clinico-pathological features. Epilepsia (Amst.), 4, 95-119.

van Hoof, F., and Hageman-Bal, M. (1967). Progressive familial myoclonic epilepsy with Lafora bodies. Electron microscopic and histochemical study of a cerebral biopsy. Acta neuropath. (Berl.), 7, 315-326.

Watson, C. W., and Denny-Brown, D. (1953). Myoclonus epilepsy as a symptom of diffuse neuronal disease. Arch. NeuroD Psychiat. (Chic.), 70, 151-168.

Yokoi, S., Austin, J. H., and Witmer, F. (1966). Isolation an characterisation of Lafora bodies in two cases of myoclonn epilepsy. Trans. Amer. neurol. Ass, 91, 116-117.

- , Kobori, H., and Yoshihara, H. (1965). Clinical and neuropathe logical studies of myoclonic epilepsy. Acta neuropath. (Berlf 4, 370-379. 